\title{
XXII. On a new method of reducing observations relating to several quantities
}

\section{F.Y. Edgeworth M.A.}

To cite this article: F.Y. Edgeworth M.A. (1888) XXII. On a new method of reducing observations relating to several quantities, Philosophical Magazine Series 5, 25:154, 184-191, DOI: $10.1080 / 14786448808628170$

To link to this article: http://dx.doi.org/10.1080/14786448808628170

曲 Published online: 29 Apr 2009.

Submit your article to this journal $[\pi$

山 Article views: 42

Q View related articles $\square$

Citing articles: 7 View citing articles 5 
Table II. gives the apparent electrochemical equivalent of copper for the different current-densities and temperatures stated in the table; it is simply the numbers in Table I. multiplied by the proper constant. The results in this table are, as in the former paper, based on the results obtained by Lord Rayleigh and Mrs. Sidgwick for silver, or $001118 \mathrm{grm}$. of silver deposited per conlomb of electricity passed through the cell. The ratio of the electrochemical equivalents of copper and silver obtained in the experiments described in my former paper has been assumed as correct (Phil. Mag. Nov. 1886). It is $\cdot 2940$ when the copper plate presents a surface of 50 square centimetres per ampere of current.

TABLE II.

\begin{tabular}{|c|c|c|c|c|c|}
\hline $\begin{array}{l}\text { Area of eatbode, } \\
\text { in square centi- } \\
\text { metres per am- } \\
\text { pere of current. }\end{array}$ & $\begin{array}{c}\text { Tempera- } \\
\text { ture, } \\
2^{\circ} \mathrm{C} .\end{array}$ & $\begin{array}{l}\text { Tempera- } \\
\text { ture, } \\
12^{\circ} \mathrm{C} \text {. }\end{array}$ & $\begin{array}{l}\text { Tempera- } \\
\text { ture, } \\
23^{\circ} \mathrm{C} .\end{array}$ & $\begin{array}{l}\text { Tempera- } \\
\text { ture, } \\
28^{\circ} \mathrm{C} .\end{array}$ & $\begin{array}{l}\text { Tempera- } \\
\text { ture, } \\
35^{\circ} \mathrm{C} \text {. }\end{array}$ \\
\hline 50 & .0003288 & 0003287 & .0003286 & .0003286 & .0003282 \\
\hline 100 & .0003288 & .0003284 & .0003283 & .0003281 & .0003274 \\
\hline 150 & .0003287 & .0003281 & 0003280 & .0003278 & .00013267 \\
\hline 200 & $\cdot 0003285$ & $\cdot 0003279$ & $\cdot 0003277$ & 0003274 & $\cdot 0003259$ \\
\hline 250 & .0003283 & $\cdot 0003278$ & .0003275 & .0003268 & .0003252 \\
\hline 300 & .0003282 & .0003278 & .0003272 & .0003262 & 0003245 \\
\hline
\end{tabular}

XXII. On a New Method of Reducing Ubservations relating to Several Quantities. By F. Y. EDGEWORTH, M.A., Lecturer at King's College, London*.

A SUBSTITUTE for the Method of Least Squares has A been proposed by me $\dagger$, based upon the following principle. The data being of the form

$$
a_{1} x+b_{1} y \ldots-v_{1}=0 ; \quad a_{2} x+b_{2} y \ldots-v_{2}=0 ; \& c .
$$

(where $v_{1}, v_{2}$, \&c. are observations of equal worth), a solution is obtainable by taking $x, y \ldots$ such that the sum of the residuals (the left-hand members of the above-written equations), each residual taken positively, should be a minimum $\ddagger$.

* Communicated by the Author.

+ Philosophical Magazine, August 1887; and Hermathena (Dublin), 1887

I This rule is derivable from the hypothesis that the law of error, the facility-curve under which the observations range, is of the form $y=\frac{h}{2} e^{-h x}$; $x$ taken positively in both directions. But the use of the rule does not commit us to the assumption of the hypothesis, The Method of Least Sum is in this respect exactly on a par with the Method of Least Squares. The rule of the latter Method is-Determine $x$ and $y$ so that the sum of 
The point thus designated must be on each of two, or more, loci analogous to the Normal equations of the ordinary method. Accordingly the intersection of the "Median loci" was at first proposed by me as the solution. But Mr. 'Turner has shown that these loci are apt to have in common, not only several points, but even lines and spaces*. Instructed by his masterly criticism, I now restate the rule as follows; confining myself, for convenience of enunciation, to the case of two unknown quantities.

Trace the observation-lines in the neighbourhood of the true point approximately knownt. Beginning at a point on one of those lines, move continually $\ddagger$ along one or other of the lines in the direction for which $\frac{d \mathrm{R}}{d s}$ is least; $\mathrm{R}$ being the sum of the residuals, each taken positively $\$$. The value of $\frac{d \mathrm{R}}{d s}$ for any path $a x+b y-v=0$ at any assigned point is thus to be ascertained. Let the sum of the $a^{\prime}$ s (coefficients of $x$ ) belonging to the lines on the right of that point be $A$; and, to

the squares of the residuals may be the least possible. This rule is derivable from, and specially correlated with, the hypothesis that the law of facility is the Probability-curve. But it is thought legitimate by Laplace and other eminent authorities to employ the rule eren where the hypothesis is not assumed. No doubt the use of either method divorced from the law of facility appropriate to it is open to logical objections. But the difficulties are not greater for one method than for the other. The present writer's explanation of the philosophical difficulty common to both methods is stated in the Appendix to a little treatise on the Art of Measurement, entitled 'Metretike' (London: Temple Co., 1887). It is briefly summaized in the 'Cambrilge Philosophical Transactions' for 1887.

* “On Mr. Edgeworth's Method of Reducing Observations relating to Several Quantities," by H. II. Turner, M.A., B.Sc., Fellow of Trinity College, Uambridge. Philosophical Magazine, December 1887.

$\dagger$ We may, as Mr. Turner says, " leare out of consideration those with large residuals." Or, more exactly, those for which the residual, dividerl by the prectsion, is large. For the residual $a x+b y-v$ represents the perpendicular let fall from the point $x y$, multiplied by the factor $\sqrt{a^{2}+b^{3}}$; which factor may be called the precision. That perpendicular, then, miglut be short, and the line might run into the little field which we have to explore, if, though the residual is large, it is matched by a large coefficient of precision.

$f$ The true point is in general on an observation-line. For, as Mr. Turner has pointed out, the Median loci are in general made up of observation-lines. The exceptions to this statement will bo noticed presently.

\$ That is, supposing all the $v^{\prime}$ s to be observations of equal worth, ranging under une and the same facility-curve. Otherwise it is proper to multiply each of the residuals entering intes $R$ by a factor proportional to the Greatest Ordinate of the corresponding facility-rurve (supposed symmetrical). See Laplace, Théor. Analyt. Suppl. 2, sub finem. 
the left, $\mathbf{A}^{\prime}$. Let the sum of the $b$ 's, above, be $\mathrm{B}$; below, $\mathrm{B}^{\prime}$. Then

while

$$
d \mathrm{R}=\left(\mathrm{A}^{\prime}-\mathrm{A}\right) d x+\left(\mathrm{B}^{\prime}-\mathrm{B}\right) d y ;
$$

$$
a d x+b d y=0, \quad \text { and } d s=\sqrt{d} \overline{x^{2}+d y^{2}} .
$$

When the starting-point is an intersection, we should put ourselves at the proximate point along the path which is being explored. To find $\frac{d \mathrm{R}}{d s}$ for another line passing through the same point, or for a neighbouring point and line, it will not be necessary to evaluate $\mathrm{A}^{\prime}, \mathrm{B}^{\prime}$ afresh. The coefficients of $d x$ and $d y$ in the expression for $d \mathrm{R}$ require alteration only in respect of the coefficients of those lines which have been crossed.

Continue moving according to these directions, until a point is reached at which $\frac{d \mathrm{R}}{d s}$ is positive for every path passing through the point. This point constitutes the solution*. It is in general unique. For, if possible, let there be two such minimum-points. Take the line joining them as the axis of $y$. Then the expression $\left(b_{1} y-v_{1}\right)+\left(b_{2} y-v_{2}\right)+\& c$., each of the bracketed terins taken positively, must be a minimum for two points on the ordinate. Which is in general absurd; being possible only in the exceptional case when, in the notation above employed, $\mathrm{B}+b$ is exactly equal to $\mathrm{B}^{\prime}$, or $\mathrm{B}^{\prime}+b$ to $\mathrm{B}$. In this rare case the solution may be indeterminate, namely any point on a certain line or even area $\dagger$.

In this event common sense seems to dictate that we should adopt the middle of the indeterminate tract as the best point; and this presumption is confirmed by a formal calculation of utility such as Laplace, in the simplest case of a single unknown quantity, has employed to discover the "most advantageous" pointf.

* The method may be illustrated thus:-Let $C-R$ (where $C$ is a constant) represent the height of a surface, which will resemble the roof of an irregularly built slated house. Get on this roof somewhere near the top, and, moving continually upwards along some one of the edges or arrêtes, climb up to the top. The highest position will in general consist of a solitary pinnacle. But occasionally there will be, instead of a single point, a horizontal ridge, or even a flat surface.

$\dagger$ This is Mr. Turner's " special case," loc. cit. pp. 468 \& 469.

$\ddagger$ Laplace, dealing with a set of observations known to have emanated from a Probability-curve (Théor. Analyt. book 2, chap. 4, art. 23), thus in effect reasons:- In the long run of cases, where we have to do with a set of observations exactly the same as the proposed set, the real point, which is the scurce from which this grouping emanated, occurs at different points with a frequency which is represented by a certain Probability- 
It may be worth while showing that, not only is the indeterminateness in question rare and remediable, but it is also apt to be slight and neglectible. For it tends to be of an order which is insignificant in comparison with the probable error to which the solution is liable. It will be sufficient to show that, in the case of a single quæsitum and observations obeying the simplest law-ranged under one and the same probability-curve-as the number of observations increases, the space which is left blank at the centre tends to become indefinitely small in comparison with the probable error of the solution by the Method of Least Squares. The Modulus of that error is $\frac{c}{\sqrt{n}}$ (where $c$ is the Modulus of the primary Probability-curve). Now consider the probability that a certain fraction of that Modulus, say $i \frac{c}{\sqrt{n}}$, measured from the centre (the real point supposed known) will have remained blank. The probability that any single observation should fall outside the space $\pm i \frac{c}{\sqrt{n}}$ may be written $\left(1-\theta\left(i \frac{c}{\sqrt{n}}\right)\right)$, where $\theta$ is the integral of the error-function. Hence the probability that all the observations should lie outside that limit is

$$
\left(1-\theta\left(i \frac{c}{\sqrt{ } n}\right)\right)^{n}
$$

Expanding and taking logarithms, we see that the logarithm of this probability is of the order $-\sqrt{n}$; that is, it becomes indefinitely improbable that the $i$ th part of the probable error should be left indeterminate. This investigation may be extended to prove the required proposition in its generality.

curve whose centre is the Arithmetic Mean of the given set (and whose Modulus is the $\frac{1}{\sqrt{n}}$ th part of the Modulus appertaining to the given observations). If, now, we must put one point as representative of all the series of points which the source may assume, the best representative, that which minimises the detriment incident to inevitable error, is the centre of the curve of sources; that is, the Arithmetic Mean of the given observations. Now had the curve of sources given by Inverse Probability consisted of a horizontal line at the centre, as in the case before us, the reasoning by which the central point is judged best would not have been affected.

I do not forget that, when the law of error is other than $y=\frac{h}{2} e^{-h x}$, this reasoning is applicable less directly, and only in virtue of the explanations referred to in the third note to p. 184 . 
The rule and the exception may be illustrated by the following example*. Let the equations be

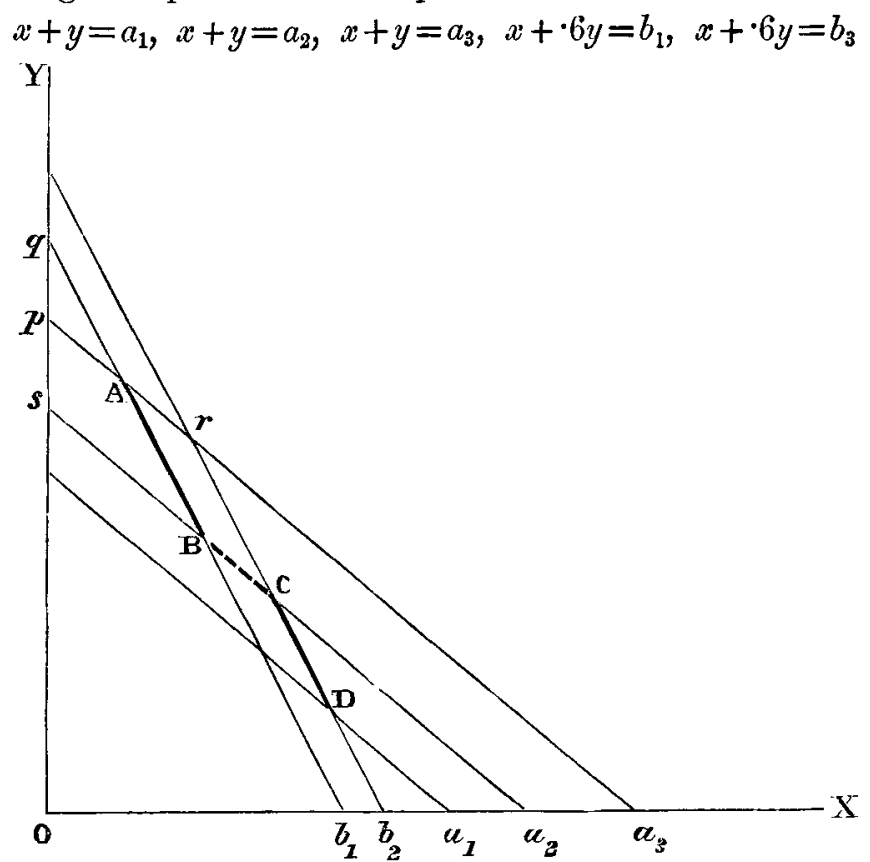

represented by the annexed diagram. Beginning at the in. tersection $\mathrm{A}$ we have, for movement in the direction $\mathrm{A} p$,

and therefore

$$
d \mathrm{R}=d y(2-1 \cdot 2) ; d s=\sqrt{2} d y^{\prime}
$$

$$
\frac{d \mathrm{R}}{d s}=+\frac{\cdot 8}{\sqrt{2}}
$$

For $\mathrm{A} q$ we have

and

whence

$$
d \mathrm{R}=-2 d x+d y(3-\cdot 6)
$$

$$
d x+\cdot 6 d y=0 ;
$$

$$
\frac{d \mathrm{R}}{d s}=+\frac{3 \cdot 6}{\sqrt{1 \cdot 36}} \cdot
$$

Again, for $\mathrm{A} r$ we have $\frac{d \mathrm{R}}{d s}=0$; and for $\mathrm{AB},=-\frac{\cdot 4}{\sqrt{2}} . \mathrm{AB}$

* This example also illustrates the possibility of the intersection between the Median loci being thoroughly indeterminate. The broken line $p \mathrm{~A} \mathrm{BCD} a_{1}$ is the locus of Median both for ordinates and coordinates. 
is therefore the required path. Proceeding to $B$ we find $\frac{d \mathrm{R}}{d s}$, for the paths $\mathrm{B} s$ and $\mathrm{B} b_{1}$, positive; and for the path $\mathrm{BC}$, zero. Also at the point $\mathrm{C}$, all the paths except $\mathrm{CB}$ present a positive increment. Hence the most probable solution is any point on the line $\mathrm{BC}$; and the best* solution is the middle of that line.

Thus the weighty objection to the new method on account of its "failure to give a unique solution" $\rightarrow$ is completely removed. It remains to consider the objection that it is not less laborious than the ordinary method.

Of course the issue cannot be decided on the score of convenience alone. We must take accuracy also into account. For this purpose we may distinguish two species of cases: $(\alpha)$ those in which the Method of Medians has an advantage in respect of accuracy, and $(\beta)$ those where the Probabilitycurve is presumed to prevail. ( $\alpha$ ) Suppose that the law of facility is "discordant," made up of two Probability-curves, thus:

$$
y=\frac{1}{2} \frac{1}{\sqrt{\pi} \mathrm{C}} e^{-\frac{x^{2}}{\mathrm{C}^{2}}}+\frac{1}{2} \frac{1}{\sqrt{\pi} c} e^{-\frac{x^{2}}{c^{2}}} .
$$

By a formula of Laplace $\neq$, the probable error of the Median is the reciprocal-of-the-Greatest-ordinate divided by $\sqrt{2 n}$; that is, in the case before us,

$$
\sqrt{\frac{\pi}{2 n}} \times \frac{1}{2} \frac{\mathrm{C} c}{\mathrm{C}+c}
$$

The corresponding error for the Arithmetic Mean prescribed by the Method of Least Squares is the square root of twice the Mean-Square-of-Error, divided by $\sqrt{n}$; that is,

$$
\frac{\sqrt{\mathrm{C}^{2}+e^{2}}}{\sqrt{\overline{2 n}}}
$$

It is evident that, if $\mathrm{C}$ and $c$ be very unequal, the former solution may be ever so much better than the latter.

$(\beta)$ In the ordinary case of laws of facility which are Probability-curves, I should like to express myself with a cautious deference to the opinion of practical astronomers. On the one hand, the probable error is increased by about twenty per cent. when we substitute the Median for the Arithmetic or Linear Mean§. On the other hand, the labour of extracting the former is rather less : especially, I should

* See note 3 to p. 186.

† Supplément 2, Théor. Anal. \$ Ibid. 
think, in the case of many unknown variables. At the same time that labour is more "skilled." There may be needed the attention of a mathematician; and, in the case of many unknowns, some power of hypergeometrical conception. Perhaps the balance of advantage might be affected by an $\grave{a}$ priori knowledge of an approximate solution. Which is, I think, a greater convenience in the case of the new method than of the received one, where the given equations are linear. Again, in cases where Discordance or other irregularity may be suspected, it will be useful to verify the result of the Method of Least Squares by the simpler method. The consilience between the two results which Mr. Turner's work exhibits is surely very satisfactory.

Moreover, in cases where the observation-equations are of the second (or higher) degrees, it seems possible that the Median should have a decided advantage over the received method. According to the latter, we must start with an approximation sufficiently close to warrant the neglect of those terms of the equations which involve the variables in the second (or higher) degrees. Otherwise the principle of Least Squares would lead at best* to cumbrous simultaneous equations of the third (or higher) degrees. But, according to the principle herein set forth, a solution is obtained by taking $x$ and $y$ such that $\mathrm{R}$, the sum of the residuals of the type $\left[a x^{2}+2 h x y+b y^{2}+2 f x+2 g y-r\right]$, each taken positively, should be the least possible. By considering the geometrical interpretation of this condition, we may see that the required point is on an observation-curve. As in the simpler case, we may climb to the position of highest probability by noting the value of $\frac{d \mathrm{R}}{d s}$ at every turn. Thus, let us start from a point $x_{0}, y_{0}$ on the curre $a_{0} x^{2}+2 h_{0} x y+b_{0} y^{2}+2 f_{0} x+2 g_{0} y=r_{0}$ : and, as before, let the coefficients of the observation-lines below and left of the initial point be dotted ; above and right, plain. Then

where

$$
\begin{aligned}
d \mathrm{R} & =2 d x\left[\left(\mathrm{~S} a^{\prime}-\mathrm{S} a\right) x_{0}+\left(\mathrm{S} h^{\prime}-\mathrm{S} h\right) y_{0}+\left(\mathrm{S} f^{\prime}-\mathrm{S} f\right)\right] \\
& +2 d y\left[\left(\mathrm{~S} b^{\prime}-\mathrm{S} b\right) y_{0}+\left(\mathrm{S} h^{\prime}-\mathrm{S} h\right) x_{0}+\left(\mathrm{S} g^{\prime}-\mathrm{S} g\right)\right] ;
\end{aligned}
$$

$$
d x\left[a_{0} x+h_{0} y+f_{0}\right]+d y\left[b_{0} y+h_{0} x+g_{0}\right]=0 .
$$

From these equations $\frac{d \mathbf{R}}{d s}$ is to be found. If it is positive, we move backwards, and vice versâ. At each intersection we take the path for which $\frac{d \mathrm{R}}{d s}$ is least.

* Even supposing the law of facility to be the Probability-curve. 
Other uses and qualifications of the method would doubtless come to light, if experts would turn their attention to the subject. It may be hoped that Mr. Turner's example will be followed by other practicul astronomers. An unquestioning acquiescence in the orthodox Method of Least Squares is the less justifiable, in so far as the doctrine, in its form of rigid exclusiveness, is not derivable from the fountain of authority, Laplace. Laplace by no means degrades the "Method of Situation" below the Method of Least Squares. He expressly prefers the former in certain cases*. Orthodoxy should not put tradition before inspiration.

XXIII. An Experimental Study on the Infuence of Magnetism and Temperature on the Electrical Resistance of Bismuth and its Alloys with Lead and Tin. By EDMOND von AUBEL, of Liege, Member of the Physical Society of Londont.

\section{Preliminary Communication.}

Biblography.

1. H. Tomlinson. Proc. Roy. Soc. London, xxxiii. p. 276 (1882).

2. Righi. Atti della $R$. Accademia dei Lincei [3], xix. p. 545 (188384) ; Journal de Physique [2], iii. p. 355 (1884).

3. Hurion. Journal de Physique [2], iv. p. 171 (1885).

4. Leduc. Journal de Physique [2], iii. p. 362 (1884), and v. p. 116 (1886).

5. Von Ettingshausen and Nernst. Wien. Ber. xciv. Abth. ii. p. 560 (1886).

6. J. Faé. Lumière électrique, xxiii. p. 169 (1887), and xxv. p. 630 (1887).

7. Goldhammer. Annalen der Physik, 1887, no. 7, p. 360.

8. Von Ettingshausen. Sitzungsberichte der Akademie der Wissenschaften zu Wien, Meeting of the 31st March, 1887.

9. Elie. Journal de Physique, September 1887.

MANY physicists have been at work upon the influence of I magnetism on the electrical conductivity of metals. The metals which have already been studied are iron, nickel, cobalt, antimony, tellurium, and especially bismuth.

The above investigations have been carried on principally with the view of discovering an explanation of Hall's phenomenon.

The present memoir is intended to fix the date of publication. Our researches were commenced last May ; since then many works have appeared on the question which we

* Théor. Analytique, Supplément 2, sub finem; referring to the simple case of a single unknown quantity. To generalize the principle there laid down is the object of this paper.

+ Communicated by the Physical Society : read January 28, 1888. 